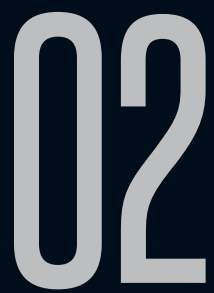

\title{
O HOMUS LOVECRAFTUS CONTRA A MODERNIDADE
}

Alexander Meireles da Silva (UFG-Catalão)

Recebido em $28 \mathrm{fev}$ 2017. Alexander Meireles da Silva Alexander Meireles Aprovado em 30 mar 2017. da Silva é Doutor em Literatura Comparada pela Universidade Federal do Rio de Janeiro (2008), Mestre em Literaturas de Língua Inglesa pela Universidade do Estado do Rio de Janeiro (2003) e Especialista em Educação a Distância pelo SENAIRJ (2003). Desde 2009 atua como Professor Adjunto de Língua Inglesa e Literaturas de Língua Inglesa da Unidade Acadêmica Especial de Letras e Linguística da Universidade Federal de Goiás - Regional Catalão, onde também é Professor permanente do Mestrado em Estudos da Linguagem da RC/UFG. Desde 2014 responde pela Chefia da Unidade Acadêmica Especial de Letras e Linguística. Já trabalhou como Professor de Literaturas de Língua Inglesa, Língua Inglesa e Teoria da Literatura em diversas instituições de ensino superior públicas e privadas no Rio de Janeiro. É autor do livro LITERATURA INGLESA PARA BRASILEIROS: curso completo de literatura e cultura inglesa para brasileiros (2005), pela editora Ciência Moderna. Suas pesquisas se concentram nas áreas das Literaturas de Língua Inglesa e da Literatura Fantástica. É idealizador do site/blog FANTASTICURSOS (www.fantasticursos. com) e do Canal do YouTube FANTASTICURSOS (www.youtube.com/fantasticursos), onde oferece conteúdo, cursos e consultoria sobre o Fantástico na Literatura, no Cinema e nos Quadrinhos nas vertentes da Fantasia, Gótico, Terror, Horror e Ficção Científica. 
Resumo: Este artigo visa analisar a presença de um homus lovecraftus dentro da ficção do escritor norte-americano Howard Phillips Lovecraft ligada às narrativas comumente chamadas de Mitos de Cthulhu. Para tanto, considera-se de que forma o pensamento de H. P. Lovecraft sobre a ostensiva presença dos imigrantes na América do início do século vinte foi traduzida em sua teratologia ficcional. Os contos "Dagon" (1917), "O Chamado de Cthulhu" (1926) e "A sombra em Innsmouth" (1927) compõem o corpus a ser analisado por meio do suporte teórico de, dentre outros, Edmund Burke (2013), Jeffrey Jerome Cohen (2000), Marshall Berman (1986) e Mary Douglas (2012). Especificamente a análise demonstrará como ao mesmo tempo em que o homus lovecraftus anuncia a inexorável chegada da Modernidade e tenta compreender seu alcance, ele se revela incapaz de suportar seu impacto sobre sua identidade.

Palavras-chave: H. P. Lovecraft; Mitos de Cthulhu; Homus Lovecraftus; Modernidade.

Abstract: This article aims to analyse the presence of a homus lovecraftus in the fiction of North-American writer Howard Phillips Lovecraft linked to narratives commonly called Cthulu Mythos. For this purpose, it is considered how H. P. Lovecraft's thinking on the ostensive presence of immigrants in early twentiethcentury America was translated into his fictional teratology. The short stories "Dagon" (1917), "The Call of Cthulhu" (1926) and "The Shadow over Innsmouth" (1931) compose the corpus to be analysed through the theoretical support of, among others, Edmund Burke (2013), Jeffrey Jerome Cohen (2000), Marshall Berman (1986) and Mary Douglas (2012). The analysis demonstrates specifically how at the same time the homus lovecraftus announces the inexorable arrrival of Modernity and tries to understand its limits, he is unable to bear its impact on his identity.

Keyword: H. P. Lovecraft; Cthulhu Mythos; Homus Lovecraftus; Modernity. 
O ano de 2017 marca não apenas os oitenta anos de morte do escritor Howard Phillips Lovecraft, mas também um século de criação de seus primeiros contos maduros escritos em 1917: "Dagon" e "A tumba", ambos publicados na revista The Vagrant respectivamente nos anos de 1919 e 1921. Estes dois contos refletem tanto as influências iniciais quanto os caminhos percorridos pela prosa lovecraftiana ao longo das próximas duas décadas de sua carreira.

Em “A Tumba” temos H. P. Lovecraft leitor de Edgar Allan Poe. Destaca-se aqui a utilização, por parte de Lovecraft, de temas e elementos presentes nos contos do autor de "Morella" (1835), "A queda da casa de Usher" (1839) e "Coração denunciador" (1843), como o sepultamento prematuro, a crença na metempsicose, a narrativa autodiegética de um personagem perturbado e a ênfase na construção do espaço da trama. Nos anos seguintes, a sombra de Poe ainda se faria sentir com maior ou menor intensidade nos temas usados em outras obras lovecraftianas, como "Ar frio" (1926), em que a ciência vem construir o espaço do sobrenatural em uma narrativa de forte ligação com "O estranho caso do Sr. Valdermar" (1845).

Mas é em "Dagon" que H. P. Lovecraft inicia o processo de construção de um sistema literário próprio, habitado por seres monstruosos oriundos dos pesadelos de sua conturbada infância e juventude. Ajudou a dar forma a esta matéria bruta o contato de Lovecraft em 1919 com a obra de Lord Dunsany, onde encontrou a base para a elaboração do panteão de criaturas do porte de Cthulhu, Yuggoth e Yog-Sothoth (RICCI, 2014, p.xxvi).

Além de Poe e Dunsany, o universo mitológico desenvolvido por H. P. Lovecraft tem sua gênese literária nos escritos de, dentre 
outros, Ambrose Bierce ("Um habitante de Carcosa"), Robert W. Chambers (O rei de amarelo), Arthur Machen (O grande deus Pã), Algernon Blackwood ("Os salgueiros") e M. R. James (Contos de fantasmas). Se há algo em comum entre estas influências que veio a capturar a imaginação de Lovecraft foi a capacidade destes escritores em revelar o sobrenatural no ordinário, não estando o mesmo atrelado a espaços tradicionais do gótico como o castelo e o cemitério. Da realidade cotidiana irrompem-se forças estranhas e ancestrais que desafiam a compreensão lógica dos homens em contato com tais poderes.

No entanto, mais do que simplesmente se colocar como um veículo para o exorcismo dos demônios internos de H. P. Lovecraft, as obras que posteriormente foram designados por seus seguidores de "Mitos de Cthulhu" (JOSHI, 2007, p.97) apresentam a visão do escritor sobre o Zeitgeist do início do século vinte na América e, mais especificamente como este artigo pretende demonstrar, sua resistência ao que se convencionou chamar de Modernidade. Esta postura, corporificada em personagens recorrentes e atitudes recorrentes, apontam para a presença de um homus lovecraftus que, ao mesmo tempo em que anuncia a inexorável chegada da Modernidade e tenta compreender seu alcance, se revela incapaz de suportar o impacto da mudança sobre sua identidade.

Mas, afinal de contas, qual é a visão de modernidade tomada aqui? O que é ser "moderno"? Com a palavra, Marshall Berman:

Ser moderno é encontrar-se em um ambiente que promete aventura, poder, alegria, crescimento, autotransformação das coisas em redor - mas ao mesmo tempo ameaça destruir tudo o que temos, 
tudo o que sabemos, tudo o que somos. [...] ela nos despeja a todos num turbilhão de permanente desintegração e mudança, de luta e contradição, de ambiguidade e angústia. (BERMAN, 1986, p.15)

Independente das possibilidades de leitura da Modernidade colocadas acima pelo crítico norte-americano Marshall Berman, elas sempre apontam para um movimento de mudança decorrente da crise no pensamento de fim do século dezenove. Na Inglaterra vitoriana, centro econômico e militar do mundo na época, esta mudança foi promovida pelo impacto das ideias científicas de Charles Darwin e a evolução das espécies e de Sigmund Freud e as pesquisas sobre o inconsciente humano, apenas para citar dois exemplos representativos. O resultado deste quadro foi uma crise que afetou de forma significativa a noção identitária do sujeito finissecular em relação as suas crenças e valores.

Na América do mesmo período, uma das manifestações mais visíveis da Modernidade foi a chegada de sucessivas ondas de imigrantes ao país, a ponto de, já na década de 1890, quatro em cada cinco moradores de Nova York serem estrangeiros, a maior taxa do tipo em qualquer outra cidade do mundo da época. Este fenômeno continuou alcançando o pico máximo de 8,8 milhões de imigrantes a chegarem à América na primeira década do século vinte (TINDALL, 1984, p.791-792).

Se por um lado este fluxo humano forneceu a mão de obra necessária para o desenvolvimento da indústria e da infraestrutura norte-americana, por outro os imigrantes foram enxergados como uma ameaça à sociedade, principalmente pelo fato da maior parte ser oriunda do leste europeu e da America Latina e não 
compartilhar das crenças culturais e religiosas do norte-americano de passado puritano e de origem anglo-saxônica. Como destaca o historiador George Brown Tindall: "As diferenças culturais confirmavam na mente dos nativistas a presunção de que os povos nórdicos da primeira imigração eram superiores aos povos eslavos e latinos da nova imigração" (TINDALL, 1984, p.793 - tradução nossa). O analfabetismo dominante entre os recém-chegados e o desconhecimento da Língua Inglesa reforçava esta impressão de atraso dos imigrantes junto a segmentos da população americana.

Nascido no seio de uma das famílias mais antigas de Providence, cidade do Estado de Rhode Island e fundada no século dezoito nos momentos iniciais da colonização puritana na América, H. P. Lovecraft sempre demonstrou inquietude com a enorme presença de estrangeiros em Nova York, onde viveu entre os anos de 1922 e 1926. No conto "Ar frio", por exemplo, publicado em 1926, o narrador sem nome que se muda para Nova York deixa claro sua repulsa aos estrangeiros residentes no hotel em que vive, revelando a visão do próprio Lovecraft sobre o assunto:

A senhoria, uma espanhola vulgar e quase barbada que atendia pelo nome de Herrero, não me aborrecia com fofocas nem com críticas a respeito da luz que permanecia acesa até o avançado da noite em meu quarto no terceiro andar; e os demais inquilinos eram tão quietos e indiferentes quanto se podia desejar, sendo a maioria deles espanhóis só um pouco acima da maior grosseira e da maior vileza. (LOVECRAFT, 2012, p.30)

Lovecraft enxergava nos estrangeiros, principalmente os não pertencentes a povos anglo-saxônicos, a face mais visível da extensa 
mudança em curso na sociedade norte-americana que ameaçava a estrutura social vigente desde a colonização puritana em fins do século dezessete e que se chocava com sua personalidade ligada a tradições. Como Denilson Earhart Ricci assinala em $O$ mundo fantástico de Lovecraft (2014): “Desde a retomada de seus escritos [em 1919] Lovecraft tornou-se assumidamente conservador, anglófilo e admirador da cultura teutônica nórdica" (RICCl, 2014, p.xxvi). Lovecraft também era profundo admirador da cultura romana e enxergava os imigrantes como uma horda de invasores bárbaros no centro de um mundo civilizado.

Convencido pela esposa a sair de sua querida Providence e se mudar para Nova York em 1922, Lovecraft retornou a sua cidade natal apenas em 1926, para dar início a fase mais produtiva de sua carreira, em que transpôs para o papel histórias de homens que voluntaria ou involuntariamente tomam conhecimento da ameaça de seres monstruosos oriundos de regiões além do alcance da civilização e tem suas vidas transformadas para sempre por esse contato. É Lovecraft expressando sua crítica a Modernidade por meio do homus lovecraftus.

Ainda que "O chamado de Cthulhu" (1926) seja uma das portas de entrada para compreender a mitologia monstruosa de H. P. Lovecraft, é em "Dagon" que são apresentados pela primeira vez alguns dos elementos que ajudam a compreender a visão do escritor sobre o Zeitgeist do começo do século vinte.

Ambientado no início da Primeira Guerra Mundial, este curto conto em que a influencia de Edgar Allan Poe se faz presente ao longo de toda a sua extensão, traz um narrador autodiegético 
perturbado mentalmente pelos acontecimentos vivenciados por ele na história. De fato, semelhante ao narrador de "O gato preto" (1843), o protagonista de "Dagon" quer deixar registrado seu relato antes de morrer. Mas, enquanto em Edgar Allan Poe esta mente perturbada pode pertencer a um assassino prestes a ser executado, um viciado sofrendo os sintomas da abstinência ou alguém sofrendo pela perda da pessoa amada, em H. P. Lovecraft o narrador costumeiramente ocupa uma posição de agente da ordem, seja ele professor, pesquisador, estudante ou, como em "Dagon", um supervisor de carga marítima.

O narrador é o primeiro elemento a ser considerado na proposta de um homus lovecraftus, pois esse é o personagem que adentra os espaços topofóbicos em busca de compreensão e, portanto, ordenamento do caos que ali reside. No entanto, o mundo lovecraftiano ligado aos mitos de Cthulhu não apenas resiste à racionalização, mas também demonstra a incapacidade do pensamento iluminista em controlá-lo. Seja tentando entender as estranhas escrituras de um monólito em uma ilha desconhecida no meio do Oceano Pacífico ou testemunhando o crescente número de imigrantes chineses em bairros antes ocupados exclusivamente por americanos de origem anglo-saxônica o homus lovecraftus se percebe inseguro diante da realidade a sua frente. Este quadro se alinha com o processo descrito por Karl Marx e Friedrich Engels, sobre a Modernidade:

[...] é o permanente revolucionar da produção, o abalar ininterrupto de todas as condições sociais, a incerteza e o movimento eternos... Todas as relações fixas e congeladas, com seu cortejo de vetustas representações e concepções, são 
dissolvidas, todas as relações recém-formadas envelhecem antes de poderem ossificar-se. Tudo que é sólido se desmancha no ar... (MARX; ENGELS, 1973, p.70 - tradução nossa)

Se para Marx e Engels "Tudo que é sólido se desmancha no ar" em H. P. Lovecraft se pode dizer que tudo que é sólido se desmancha no mar, dado a presença ostensiva do oceano ao longo de suas narrativas para expressar o impacto da Modernidade sobre o homus lovecraftus. Essa leitura vai ao encontro do simbolismo do mar conforme colocado por Jean Chevalier e Alain Gheerbrant:

[...] o mar simboliza um estado transitório entre as possibilidades ainda informes as realidades configuradas, uma situação de ambivalência, que é a de incerteza, de dúvida, de indecisão, e que pode se concluir bem ou mal. Vem daí que o mar é ao mesmo tempo a imagem da vida e a imagem da morte. (2012, p.592)

O contínuo dinamismo do mar, a falta de fixidez das águas habitadas por seres monstruosos evoca a análise realizada pela pesquisadora Mary Douglas sobre o livro bíblico do Levítico enquanto normatizador das categorias de pureza e impureza dos alimentos para os israelitas.

Publicada em Pureza e perigo (1966), a pesquisa trata dos esquemas de categorização cultural para se definir que a sacralidade do corpo humano está na sua condição de pertencimento a uma categoria cultural única. Estas categorias são percebidas de forma inconsciente pelo homem e dão sentido e orientação para a sua normatização da natureza. Assim sendo, o homem deve evitar contato com os seres que transgridem esses limites de forma a evitar a impureza: 
Para compreender este esquema precisamos de regressar ao Genesis e à Criação, onde descobrimos uma primeira classificação de conjunto: a tripla distinção entre a terra, as águas e o firmamento. O Levítico retoma este esquema e atribui a cada elemento os animais adequados. Ao firmamento, as aves voadoras com duas pernas. À água, os peixes escamosos que nadam com barbatanas. A terra, os animais de quatro patas e que saltam ou caminham. Qualquer grupo de criaturas que não obedeça ao modo de locomoção que lhe é atribuído no seu elemento é contrário à santidade. $\mathrm{O}$ indivíduo que entre em contacto com um destes animais, fica desautorizado a entrar no Templo. (2012, p.44-45)

Oriundo de um mundo marcado pela tradição, costumes e regras, o homus lovecraftus em "Dagon" percebe que o mar onde ele exercia sua profissão de marinheiro, seu mundo diário, é apenas uma fina cortina que esconde outra realidade habitada por seres que desafiam os esquemas mencionados por Mary Douglas:

Não consigo pensar nas profundezas oceânicas sem estremecer ao imaginar as coisas inomináveis que neste exato momento podem estar deslizando e arrastando-se pelo fundo viscoso, rendendo homenagens a antigos ídolos de pedra e esculpindo sua execranda imagem em obeliscos submarinos de granito úmido. (LOVECRAFT, 2012, p.26)

A utilização por Lovecraft dos verbos "deslizando" e "arrastando" ao invés de "nadando" para descrever o movimento dos seres aquáticos imaginados pelo narrador deixa entrever a posição híbrida destas criaturas e seu efeito sobre a constituição mental do marinheiro. A menção adicional às palavras "viscoso" 
e "úmido", termos ligados ao entre-lugar, reforça a leitura de que o sentimento de estremecimento mencionado pelo personagem decorre da transgressão do mundo aquático desvelado.

Enquanto conto que apresenta os elementos iniciais da mitologia de Cthulhu, "Dagon" traz o oceano em posição análoga ao que seria posteriormente ocupado também pelo universo em outras histórias, como na novela A cor que caiu do espaço (1927). A importância desses espaços de dimensões aparentemente infinitos como fonte para o que foi denominado mais tarde de "Horror Cósmico" (STABLEFORD, 2007, p.65) está presente na explicação dada pelo próprio escritor sobre sua visão de fantástico. Para H. P. Lovecraft as histórias devem conter

Uma certa atmosfera inexplicável e empolgante de pavor de forças externas desconhecidas precisa estar presente; e deve haver um indício, expresso com seriedade e dignidade condizentes com o tema, daquela mais terrível concepção do cérebro humano - uma suspensão ou derrota maligna e particular daquelas leis fixas da Natureza que são nossa única salvaguarda contra os assaltos do caos e dos demônios dos espaços insondáveis. (2008, p.17)

O "pavor de forças externas desconhecidas" é o que sente o homus lovecraftus diante da descoberta dos "demônios dos espaços insondáveis" contra os quais as "leis fixas da Natureza" desmancham no ar da Modernidade.

Mas qual são as formas e efeitos desses demônios?

Então, de repente eu vi. Com um leve rumor que marcou sua chegada à superfície, a coisa apareceu acima das águas escuras. Vasto como um Polifemo, horrendo, aquilo dardejava como um pavoroso 
monstro saído de algum pesadelo em direção ao monólito, ao redor do qual agitava os braços escamosos ao mesmo tempo que inclinava a cabeça hedionda e emitia sons compassados. Acho que foi naquele instante que perdi a razão. (LOVECRAFT, 2012, p.25)

Monstruoso pelo tamanho e pela mistura da forma humanoide com aquática, a criatura vislumbrada pelo marinheiro em "Dagon" é puro horror além da capacidade da compreensão humana e provoca o questionamento sobre a eventual presença do Sublime nos termos burkeanos no conto:

Tudo que seja de algum modo capaz de incitar as idéias de dor e de perigo, isto é, tudo que seja de alguma maneira terrível ou relacionado a objetos terríveis, ou que atue de um modo análogo ao terror, constitui uma fonte do sublime, isto é, produz a mais forte emoção do que o espírito é capaz. (BURKE, 2013, p.59)

No entanto, e isto reforça a proposta da existência do homus lovecraftus enquanto representação do impacto da Modernidade sobre o americano de origem protestante e anglo-saxônica, o narrador em "Dagon" não encontra nenhuma atenuação compensatória para a dor e perigo, que fragmenta o seu ser, causada pela visão da criatura. De fato, ao fim da narrativa e do contato com forças primais resta ao homus lovecraftus apenas a morte, a insanidade ou a contaminação pelo monstruoso (RALICKAS, 2007, p.365).

Cabe destacar aqui neste ponto brevemente que a despeito de "Dagon" apresentar elementos que também estão presentes nas obras que vieram a compor os Mitos de Cthulhu, ele deve ser entendido primordialmente como um ensaio de Lovecraft para a 
criação de sua mitologia. A característica mais visível deste fato é a própria criatura que surge diante do estupefato narrador.

Diferente dos outros seres monstruosos criados pela imaginação de H. P. Lovecraft que habitam o fundo dos oceanos, cidades perdidas nos confins do mundo, o espaço profundo ou outras dimensões, a criatura que dá nome ao conto "Dagon" tem base na mitologia do antigo Oriente Médio, estando relacionada ao deus semita, homônimo venerado pelos filisteus. O culto a Dagon, ou Dagan como também é chamado, remonta a 2500 a.C. e sua descrição física variava entre um ser metade homem e metade peixe ou um homem coberto de escamas. Por conta disso, ainda há debate entre estudiosos das razões pela qual um ser que remete ao mar ser o responsável pela fertilidade, agricultura e colheitas. Apresentado na mitologia como o pai do deus Baal, Dagon possui registro na Bíblia, atestando a sua força simbólica entre os povos da época.

No conto de Lovecraft, não há nenhuma indicação direta entre o gigantesco ser abissal que surge diante do narrador e a divindade cultuada pelos povos da Antiguidade. A menção ao deus ocorre quando, após voltar à civilização, o narrador, na sua condição de homus lovecraftus, busca explicação para o inexplicável tomando como referência o conhecimento apreendido pela cultura: "Certa vez falei com um etnólogo famoso e diverti-o com perguntas um tanto peculiares sobre a antiga lenda filistina de Dagon, o DeusPeixe; mas logo, ao perceber que o estudioso era irremediavelmente ordinário, desisti das minhas perguntas" (LOVECRAFT, 2012, p.26). A tentativa, todavia, se mostra infrutífera e isso leva o marinheiro a entrar em uma espiral decadente de desequilíbrio mental que o 
leva primeiro ao vício da morfina e depois a visões de que a criatura aquática está em seu encalço. Por fim, este homem racional não consegue sustentar o peso de outra realidade regida por forças desconhecidas e ameaçadoras que aguardam o momento de se revelar e decide se suicidar. O fechamento do conto mais uma vez evoca Edgar Allan Poe ao deixar aberto se o que ele enxerga é fato ou produto de sua imaginação doentia: "O fim está próximo. Ouço um barulho na porta, como o de um enorme corpo escorregadio batendo contra a madeira. Jamais vão me encontrar. Meu Deus, aquela mão! A janela! A janela!" (LOVECRAFT, 2012, p.26).

Outra narrativa em que há a mesma tentativa de dar significado ao desconhecido a partir do conforto do registro cultural sobre a divindade semítica Dagon é "A sombra em Innsmouth" (1931). Nesta que é a segunda história em que Dagon é mencionado, mas não tem seu surgimento vinculado diretamente aos seres que aparecem na trama, vemos um estudante movido pela vontade de conhecer os mistérios que cercam a pequena e isolada cidade litorânea de Innsmouth. Ao chegar ao local ele percebe que a maioria da população nativa apresenta uma estranha aparência anfíbia herdada de misteriosos antepassados e realizam cerimônias religiosas no templo chamado A Ordem de Dagon.

$\mathrm{Na}$ medida em que se familiariza com a história local, este jovem homus lovecraftus descobre que, em tempos passados, o capitão Obed Marsh fez um acordo com criaturas aquáticas visando recuperar a prosperidade econômica de Innsmouth. A partir de um acordo com tais seres ele institui a Ordem de Dagon na cidade. No entanto, a narrativa nunca esclarece se foram as criaturas que deram nome ao templo em alusão ao seu deus ou se foi Obed Marsh 
que batizou o local com tal nome com base na antiga divindade dos filisteus. As "vestimentas peculiares" (LOVECRAFT, 2014, p.204) e a "vultuosa batina" (LOVECRAFT, 2014, p. 205) usada pelo sacerdote local reforçam essa ligação com a indumentária utilizada pelos sacerdotes da Antiguidade.

Uma possível resposta para explicar a identidade da criatura Dagon não está em "Dagon" ou em "A sombra em Innsmouth", mas sim no conto "O chamado de Cthulhu" (1926) cuja importância é assinalada pelo crítico S. T. Joshi:

[...] foi somente em "O chamado de Cthulhu" (1926) que se pode dizer que os Mitos de Cthulhu [...] passaram a ter existência genuína; pois foi somente aqui que todos os quatro ícones auxiliares - topografia, conhecimento oculto, deuses, e cosmicismo - são combinados pela primeira vez em um conjunto coerente. (2007, p.102 - tradução nossa)

Dentro da proposta deste artigo em examinar a presença de um homus lovecraftus como crítica de H. P. Lovecraft à Modernidade, "O chamado de Cthulhu" tem papel chave por ter sido concebido após o retorno do escritor a sua cidade natal de Providence, depois de ter passado quatro anos em Nova York. Na bagagem de volta, além de seus pertences, Lovecraft também trouxe as lembranças de suas tentativas para emplacar sua carreira como escritor e também suas impressões negativas da cidade na qual mais se evidenciou o enorme fluxo de imigrantes estrangeiros de diferentes nacionalidades, línguas e culturas que se chocavam com a tradicional cultura norte-americana de base puritana e anglosaxônica. Se S. T. Joshi menciona a topografia, o conhecimento 
oculto, os deuses, e o cosmicismo como os quatro elementos que promovem a unidade dos Mitos de Cthulhu, pode ser dito que a questão racial é o elo entre eles.

"O chamado de Cthulhu" traz um narrador anônimo que, ao herdar os pertences de seu falecido tio pesquisador, o professor George Gammell Angell, descobre evidências que uma raça de seres extraterrestres, liderados por uma criatura chamada Cthulhu, chegou a terra há milhões de anos, oriunda das profundezes do espaço sideral e aqui construiu uma cidade de arquitetura tenebrosa chamada R'lyeh.

Ambientado nos últimos anos da década de 1920, o conto se estrutura em três partes sendo a primeira centrada na abertura de uma misteriosa caixa na qual o narrador encontra um pequeno artefato de barro, um manuscrito e recortes de jornal coletados pelo tio. A primeira coisa que chama a atenção do narrador são os entalhes na peça de barro, principalmente a que traz a primeira representação na ficção lovecraftiana da criatura que posteriormente se descobre ser Cthulhu:

Se eu disser que minha fantasia extravagante conjurava ao mesmo tempo as imagens de um polvo, de um dragão e de uma caricatura humana, não incorro em nenhum tipo de infidelidade ao espírito da coisa. Uma cabeça polpuda, com tentáculos, colmava um corpo grotesco e escamoso com asas rudimentares; mas era a silhueta da figura o que a tornava ainda mais horrenda. (LOVECRAFT, 2012, p.99-100)

Tomando como base o olhar de H. P. Lovecraft sobre o perfil dos imigrantes que chegavam à Nova York pertencente a diferentes 
nacionalidades e culturas, não se pode subestimar a importância do elemento racial na teratologia lovecraftiana. Como assinala Jeffrey Jerome Cohen no ensaio "A cultura dos monstros: sete teses" (2000): "O monstro nasce nessas encruzilhadas metafóricas, como a corporificação de um certo momento cultural - de uma época, de um sentimento e de um lugar" (COHEN, 2000, p.26).

Se em "Dagon" o jovem escritor de 1917 ensaia a concepção de um ser monstruoso habitante das profundezas do oceano metade homem e metade criatura marinha que remete a uma divindade semítica, em "O chamado de Cthulhu", após quatro anos de forçada convivência com imigrantes indesejados, temos a primeira versão madura de várias outras composições híbridas que se seguiriam vindo a formar os Mitos de Cthulhu.

Hibridismo é, de fato, a palavra por trás do processo criativo monstruoso de Lovecraft e que encontra sua materialização em um ser que congrega em seu corpo água ("cabeça polpuda com tentáculos"), ar ("asas rudimentares") e terra ("caricatura humana"), subvertendo as categorias culturais elencadas desde o Gênesis bíblico mencionadas por Mary Douglas.

O incômodo sentido pelo homus lovecraftus diante da imagem do horrendo Cthulhu dentro do conto de 1926 se alinha com o relato de H. P. Lovecraft registrado em carta de 21 de agosto do mesmo ano para o amigo e também escritor de literatura fantástica Frank Belknap Long, no qual ela critica a composição multicultural de Nova York:

Como em nome de Deus o homem branco de sensibilidade e autorrespeito pode continuar a viver na confusão de sujeira asiática em que a 
região se tornou - com marcas e lembretes desta praga de gafanhotos por todos os cantos - está totalmente além da minha compreensão [...]. (LOVECRAFT, 1968)

A sensibilidade do homem branco (e do homus lovecraftus), mencionada por Lovecraft, está também representada em "O chamado de Cthulhu" no personagem de Henry Anthony Wilcox. "Filho mais moço de uma excelente família" (LOVECRAFT, 2012, p.100), Wilcox é descrito como um jovem e excêntrico arquiteto portador de "hipersensibilidade psíquica" (LOVECRAFT, 2012, p.101) que é assombrado por sonhos de uma imensa cidade ciclópica de onde se ouve duas palavras: "Os dois sons repetidos com maior frequência eram aqueles representados pelas letras 'Cthulhu' e 'R'lyeh'” (LOVECRAFT, 2012, p.102). De fato, não apenas o jovem Wilcox, mas alguns poetas, artistas e também algumas pessoas transtornadas no mundo sentiram a presença de Cthulhu em sua cidade submersa de R'lyeh. Dentre estes últimos, encontramos o caso de "um suicídio noturno em Londres, em que um homem adormecido atirou-se da janela após soltar um grito horripilante" (LOVECRAFT, 2012, p.105). Seria este o narrador anônimo de "Dagon" em um diálogo entre os textos lovecraftianos comumente encontrado na ficção do escritor? Dentro desta possibilidade de leitura, o marinheiro teria chegado acidentalmente à ilha perdida de R'lyeh? A criatura híbrida que surge diante do marinheiro seria, portanto, não uma releitura do deus semítico Dagon, mas simplesmente uma das criaturas que cultuam Cthulhu e aguardam o retorno de seu senhor? Fica mais este mistério no mundo lovecraftiano. 
Mas é na segunda parte do conto "O relato do inspetor Legrasse" que se percebe o posicionamento do escritor sobre outros povos e raças que não pertencem ao mundo anglo-saxônico.

Se a primeira parte do manuscrito deixado pelo professor Angell trata dos estranhos sonhos compartilhados por pessoas de sensibilidade exacerbada ou perturbados sobre uma criatura ancestral repousando em sua cidade colossal, a segunda parte trata das investigações de especialistas acadêmicos e do investigador da polícia John Raymond Legrasse sobre a influência que Cthulhu e os Deuses Antigos exercem sobre diferentes grupos e seitas em diferentes lugares do mundo.

É nesta parte da narrativa que o leitor descobre que, em um evento acadêmico no qual participou, o tio do narrador encontrou outros pesquisadores e o próprio inspetor Legrasse envolvidos em diversas manifestações do culto a Cthulhu espalhadas pelo mundo. Mas, o que chama a atenção aqui, são os tipos humanos citados por H. P. Lovecraft como seguidores da ancestral criatura.

Sendo objeto do culto de "esquimós degenerados" (LOVECRAFT, 2012, p.108), praticantes de "orgias vodu" (LOVECRAFT, 2012, p.105) no Haiti, tribos africanas de "balbucios nefastos" (LOVECRAFT, 2012, p.105), nativos das Filipinas (LOVECRAFT, 2012, p.105) e entre negros e mulatos cabo-verdianos "degradados e ignorantes" (LOVECRAFT, 2012, p.113), Cthulhu é o deus de grupos humanos enxergados pelo autor de "O chamado de Cthulhu" como pertencentes a um mundo de atraso e barbarismo que ameaça o status quo do mundo civilizado do homus lovecraftus. São estes representantes de um mundo primitivo que, ao se tornarem imigrantes na América, são 
enxergados por H. P. Lovecraft paradoxalmente como os arautos do caos da Modernidade, ameaçadora da tradição civilizatória. Como Lovecraft confessa em carta a Frank Belknap Long sobre a invasão imigrante na sua região natal da Nova Inglaterra:

Na Nova Inglaterra nós temos nossas próprias maldições locais... na forma de Portugueses simiescos, italianos sulistas indescritiveis, e francocanadenses tagarelas. Falando de forma geral, nossa maldição é latina da mesma forma que a sua é semítico-mongoloide, o africano do Mississipi, o eslavo de Pittsburgh, o mexicano do Arizona e o sino-japonês californiano. (LOVECRAFT, 1968)

Mas, se os imigrantes indesejados não podem ser repelidos e já estão inseridos no país, qual será a consequência dessa aproximação entre eles e os "americanos verdadeiros"? Talvez o maior receio do homus lovecraftus seja justamente ver sua identidade contaminada por esses indivíduos. Este é o temor expresso na novela em "A sombra em Innsmouth".

O problema mongoloide de Nova York está longe de ser simples. A cidade está suja e execrável - Sai de lá com a sensação de ter sido contaminado pelo contato, e anseio por alguma solução de esquecimento para tirar isso de mim! (LOVECRAFT, 1968)

As palavras de H. P. Lovecraft em carta de 21 de agosto de 1926 endereçada a Frank Belknap Long não deixam dúvidas sobre o seu posicionamento contra o contato com a cultura imigrante, algo também observado na América do início do século vinte.

A América dos anos entre a Primeira Guerra Mundial e a Segunda Grande Guerra foi palco de um nativismo contrário ao 
longo processo de entrada de estrangeiros que havia se originado desde os primórdios dos Estados Unidos. Este quadro se alinhou com as ideias eugenistas disseminados em diversos países do mundo no período.

No caso específico dos Estados Unidos, segundo o historiador George Brown Tindall (1984, p. 986), as ideias eugenistas acharam um veículo de expressão através dos livros The Passing of the Great Race (1916), de Madison Grant, sendo a "grande raça" do título os povos nórdicos e The Rising Tide of Color (1920), de Lothrop Stoddard. Na esfera política, ao fim da Primeira Guerra Mundial, o Congresso Americano passou o Ato de Imigração Emergencial de 1921, que dificultou a entrada de imigrantes nos Estados Unidos.

Todo este cenário aponta para o fato de que, conforme assinala Caio Alexandre Bezarias em Funções do mito na obra de H. P. Lovecraft (2006), a presença de grupos culturais e étnicos variados dentro do país e o choque com a tradição anglófila dos norteamericanos representou uma das expressões mais significativas da modernização do país:

A presença dos mestiços e imigrantes que tinham tomado de assalto os espaços abertos das cidades - despreparadas para recebê-los em tamanha quantidade, o que gerou inúmeras tensões e conflitos entre eles e os norte-americanos nascidos em solo local - foi uma das manifestações mais visíveis, tensas e vivas da expansão da economia industrial Estados Unidos afora... (BEZARIAS, 2006, p.44)

A visão racista dominante no período expresso, por exemplo, na crença da degeneração de raças, é notado na aparência física 
do motorista do ônibus de Innsmouth conforme a descrição do narrador Robert Olmstead:

Suas peculiaridades certamente não pareciam asiáticas, polinésias, levantinas ou negroides, embora eu pudesse ver por que as pessoas o consideravam estrangeiro. Eu mesmo teria pensado mais em degeneração biológica que em origem estrangeira. (LOVECRAFT, 2014, p.200-201)

Após descobrir que os moradores da cidade são descendentes de criaturas híbridas entre o humano e o anfíbio e ser perseguido por sua investigação, Robert Olmstead consegue fugir de Innsmouth, mas a cidade jamais sai dele.

Ao pesquisar sobre sua ancestralidade, Olmstead descobre que o capitão Obed Marsh, o responsável por começar a hibridização entre humanos e as criaturas aquáticas, era seu trisavô. Esta revelação se torna fonte de angústia para o narrador pelo fato dele desconhecer a identidade da trisavó. Ao fim da história, no entanto, o homus lovecraftus Robert Olmstead descobre que o contato com os habitantes de Innsmouth se tornou maior do que ele desejava:

Foi então que comecei a estudar meu reflexo no espelho com um espanto crescente. A lenta degradação causada pela doença não era prazerosa de se observar [...] Uma noite eu tive um sonho aterrador, no qual encontrei minha avó no fundo do mar. [...] Aquela manhã o espelho definitivamente mostrou que eu havia adquirido o aspecto de Innsmouth. (LOVECRAFT, 2014, p.248-249)

Tem-se aqui na ficção de H. P. Lovecraft um temor recorrente trabalhado também nas narrativas góticas inglesas finisseculares em obras como, por exemplo, "A marca da besta" (1890), de 
Rudyard Kipling, em que a integralidade da identidade europeia é ameaçada pelo contato do indivíduo branco protestante com a cultura estrangeira tida como pagã (WARWICK, 1998, p.261-262).

Todavia, se no conto de Rudyard Kipling o inglês transformado em lobisomem consegue se livrar de sua maldição, restaurando assim sua identidade, na ficção lovecraftiana o contato e a contaminação decorrente do contato com o Outro, é um caminho sem volta, e cabe ao homus lovecraftus abraçar sua condição, enlouquecer ou se suicidar.

Refletindo um Zeitgeist marcado pelo impacto das ideias científicas em diversas áreas da experiência humana, pela crise política e econômica e pela eclosão da Primeira Guerra Mundial, a Literatura das primeiras décadas do século vinte foi marcada por hollow men (T. S. Eliot) e homus cinematographicus (João do Rio) que tentaram expressar a angústia da Modernidade já anunciada nas Artes pela figura andrógina em crise no quadro O Grito (1893), de Edvard Munch. Dentro deste contexto, o homus lovecraftus se coloca como um representante do insólito ficcional que tenta, sem sucesso, manter suas tradições e valores em meio a um mundo em rápida transformação devido ao discurso racionalista e a rápida e tensa incorporação de olhares diversos.

\section{REFERÊNCIAS}

BERMAN, Marshall (1986). Tudo que é sólido desmancha no ar: A aventura da modernidade. São Paulo: Companhia das Letras.

BEZARIAS, Caio Alexandre (2006). Funções do mito na obra de H. P. Lovecraft. Dissertação de Mestrado em Letras. São Paulo: Faculdade de Filosofia, Letras e Ciências Humanas, Universidade de São Paulo. 
BURKE, Edmund (2013). Uma investigação filosófica sobre a origem de nossas idéias do sublime e do belo. Campinas, SP: Papirus.

CHEVALIER, Jean; GHEERBRANT, Alain (2012). "Mar". In: Dicionário de símbolos. 11.ed. Rio de Janeiro: José Olympio. p.592-593.

COHEN, Jeffrey Jerome (2000). "A cultura dos monstros: sete teses". In: SILVA, Tomaz Tadeu. (Orgs.). Pedagogia dos Monstros: Os prazeres e os perigos da confusão de fronteiras. Belo Horizonte: Autêntica, p.23-60.

DOUGLAS, Mary (2012). Pureza e perigo. São Paulo: Perspectiva (Debates; 120). ENCYCLOPEDIA BRITANNICA. "Dagon". https://global.britannica.com/topic/ Dagan. Acesso em 26.Fev.2017.

JoSHI, Sunand Tryambak (2007). "The Cthulhu Mythos". In: Icons of Horror and the Supernatural: An Encyclopedia of Our Worst Nightmares. (Vol. 1 \& 2). London: Greenwood Press. p.97-128.

LOVECRAFT, Howard Phillips (2014). "A sombra em Innsmouth". In RICCI, Denílson Earhart (Orgs.). O mundo fantástico de H. P. Lovecraft: Antologia contos, poesias e ensaios. 2ed. Jundiaí, SP: Clock Tower. p.191-249.

. (2012). "Ar frio". In: O chamado de Cthulhu e outros contos. São Paulo: Hedra. p.29-38.

. (2012). "Dagon". In: O chamado de Cthulhu e outros contos. São Paulo: Hedra. p.21-27.

. (2012). "O chamado de Cthulhu". In: O chamado de Cthulhu e outros contos. São Paulo: Hedra. p.97-132.

(2008). O horror sobrenatural em literatura. São Paulo: Iluminuras.

(1968). "From Lovecraft to Frank Belknap Long, August 21, 1926" (1926). DERLETH, August, WANDREI, Donald (Eds.). Selected Letters // (1925-1929). By H.P. Lovecraft, Sauk City, WI: Arkham House Publishers Inc.

MARX, Karl; ENGELS, Friedrich (1973). The Communist Manifesto. In: Revolutions of 1848. Harmondsworth: Penguin Books.

RALICKAS, Vivian. (2007). "'Cosmic horror' and tue Question of the Sublime in Lovecraft". Journal of the Fantastic in the Arts. Vol. 18, n. 3, 364-398. In https://pt.scribd.com/doc/19744674/Cosmic-Horror-and-the-Question-of-theSublime-in-Lovecraft. Acesso em 25.Fev.2017. 
RICCI, Denílson Earhart (2014). "Biografia de H. P. Lovecraft". In: RICCI, Denílson Earhart (Orgs.). O mundo fantástico de H. P. Lovecraft: Antologia - contos, poesias e ensaios. 2.ed. Jundiaí, SP: Clock Tower, p.xix-xxxvii.

STABLEFORD, Brian (2007). "The Cosmic Horror". In: JOSHI, S. T. Icons of Horror and the Supernatural: An Encyclopedia of Our Worst Nightmares. (Vol. 1 \& 2). London: Greenwood Press. p.65-96.

TINDALL, George Brown (1984). America: A narrative history. New York: W. W. Norton \& Company.

WARWICK, Alexandra (1998). "Colonial Gothic". In: MULVEY-ROBERTS, Marie. The Handbook to Gothic Literature. New York: New York University Press. p.261-262. 